tuyến giai đoạn di căn được điều trị bằng liệu pháp ức chế androgen [2].

Về lợi ích về sống thêm, thời gian sống thêm không tiến triển (PFS) trung bình của nhóm bênh

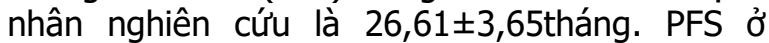
nhóm cắt tinh hoàn ngoại khoa là 22,62 3,45tháng, ở nhóm cắt tinh hoàn nội khoa là

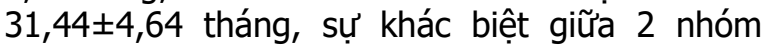
không có ý nghĩa thống kê với $\mathrm{p}=0,138$. Tuy cơ chế 2 phương pháp cắt tinh hoàn khác nhau nhưng phần lớn bệnh nhân cuối cùng sẽ tiến triển đến kháng cắt tinh hoàn trong vòng 2-3 năm. Ung thư tiên liệt tuyến giai đoạn kháng cắt tinh hoàn (mCRPC) trước đây được gọi là kháng với điều trị nội tiết, tuy nhiên gần đây với những hiểu biết sâu hơn về cơ chế tiến triển theo các con đường khác nhau (phụ thuộc và không phụ thuộc androgen), androgen vẫn đóng một vai trò rất quan trọng trong chức năng và phát triển của tế bào ung thư kháng cắt tinh hoàn.

\section{KẾT LUÂN}

Liệu pháp ức chế androgen là điều trị nền tảng và hiệu quả trong ung thư tiền liệt tuyến giai đoạn di căn. Cụ thể là:

- Sau 3 tháng điều trị, các triêu chứng lâm sàng đáp ứng thuyên giảm đáng kể.

- Bao gồm 71,8\% bệnh nhân lựa chọn cắt tinh hoàn ngoại khoa, $28,2 \%$ cắt tinh hoàn nội khoa.

- Thời gian sống thêm không tiến triển (PFS) trung bình là 26,61 $\pm 3,65$ tháng.
- PFS ở nhóm cắt tinh hoàn ngoại khoa là $22,62 \pm 3,45$ tháng, ở nhóm cắt tinh hoàn nội khoa là $31,44 \pm 4,64$ tháng, sự khác biệt giữa 2 nhóm không có ý nghĩa thống kê.

\section{TÀI LIÊU THAM KHẢO}

1. Ferlay J., Colombet M., Soerjomataram I. và cộng sự. (2019). Estimating the global cancer incidence and mortality in 2018: GLOBOCAN sources and methods. Int J Cancer, 144(8), 19411953.

2. Tâm L.T.K. đánh giá kết quả điều trị nội tiết ung thư tuyến tiền liệt giai đoạn iv. 136.

3. Gandaglia G., Abdollah F., Schiffmann J. và cộng sự. (2014). Distribution of metastatic sites in patients with prostate cancer: A populationbased analysis. The Prostate, 74(2), 210-216.

4. Loblaw D.A., Mendelson D.S., Talcott J.A. và cộng sứ. (2004). American Society of Clinica Oncology recommendations for the initial hormonal management of androgen-sensitive metastatic, recurrent, or progressive prostate cancer. J Clin Oncol Off J Am Soc Clin Oncol, 22(14), 2927-2941.

5. Conn P.M. và Crowley W.F. (1991). Gonadotropin-releasing hormone and its analogues. N Engl J Med, 324(2), 93-103.

6. Waxman J., Man A., Hendry W.F. và cộng sự. (1985). Importance of early tumour exacerbation in patients treated with long acting analogues of gonadotrophin releasing hormone for advanced prostatic cancer. $\mathrm{Br}$ Med J Clin Res Ed, 291(6506), 1387-1388.

7. Kaisary A.V., Tyrrell C.J., Peeling W.B. và cộng sứ. (1991). Comparison of LHRH analogue (Zoladex) with orchiectomy in patients with metastatic prostatic carcinoma. Br J Urol, 67(5), 502-508.

\title{
NGHIÊN CỨU HIẾU QUẢ CHUYỂN PHÔI NANG TRŨ ĐÔNG VÀ SỐ MộT YẾU TỐ LIÊN QUAN TẠI BẾNH VIỆN HỖ TRỢ SINH SẢN VÀ NAM HOC ĐỨC PHÚC
}

\author{
Phùng Thị Sơnn ${ }^{1}$, Nguyễn Thị Liên Hương ${ }^{2}$, Nguyễn Trung $\mathrm{Nam}^{3}$
}

\section{TÓM TẮT}

Mục tiêu: Xác định được tỷ lệ sông sau rã đông của phôi nang và xác định tỷ lệ có thai của chuyển phôi nang trữ đông. Đối tượng và phương pháp nghiên cứu: Nghiên cứu hồi cứu, đánh giá tỷ lệ sống

\footnotetext{
${ }^{1}$ Bệnh Viện Hỗ trợ sinh sản và Nam học Đức Phúc ${ }^{2}$ Bệnh viện Phụ Sản Trung Ương

${ }^{3}$ Viện Công nghệ sinh học - Viện Hàn lâm Khoa học và Công nghệ Việt Nam

Chịu trách nhiệm chính: Phùng Thi Sơn

Email: sonphunghus@gmail.com

Ngày nhận bài: 3.8.2021

Ngày phản biện khoa học: 30.9.2021

Ngày duyệt bài: 6.10 .2021
}

của phôi nang sau rã đông và tỷ lê có thai của 365 trường hợp chuyển phôi nang tại Bệnh viện Hỗ trơ sinh sản (HTSS) và Nam học Đức P̉húc, trong thời gian từ tháng 1 đến hết tháng 8 năm 2021. Kết quả: Từ tháng 1/2021 đến tháng 8/2021 có 365 trường hợp phù hợp tiêu chuẩn nghiên cứu. Tỷ lệ sống sau rã đông 99,85\%. Tỷ lệ $\beta$-hCG dương tính và tỷ lệ mang thai lâm sàng của nhóm này lần lượt là $74,79 \%$ và $67,12 \%$. Tỷ lệ làm tổ của phôi là 40,35 \%. Kết luận: Kết quả có thai là khá cao khi chuyển phôi nang trữ đông và trường hợp tiên lượng tốt chỉ nên chuyển 1 phôi có chất lượng tốt hoặc phôi trung bình nên chuyển kèm thêm 1 phôi tốt, khá, trung bình.

\section{SUMMARY \\ A STUDY ON FROZEN EMBRYO TRANSFER EFFECIENCY AND SOME AFFECTED FACTORS}




\section{AT DUC PHUC HOSPITAL OF ASSISTED} REPRODUCTION AND ANDROLOGY

Objectives: To evaluate the results of frozen embryo transfer include the percentage of embryos that survive thawing as well as pregnancy rate. Subject and methods: Retrospective descriptive study on 365 medical records at Duc Phuc Hospital of Assisted Reproduction and Andrology, from January to October 2021. Results: There are 365 cases carried out during 01/2021 - 08/2021 which match the researching standard. Survival rate after thaw $99.85 \%$. The positive beta-HCG rate and clinical pregnancy rate of this group are $74.79 \%$ and clinical pregnancy $66.85 \%$. The embryo implantation rate is $40.35 \%$. Conclusion: The pregnancy rate in frozen embryo cycles is extremely high and in case of good prognosis, only 1 embryo of good quality should be transferred, with bad embryos we should transfer 2 embryos.

\section{I. ĐẶT VẤN ĐỀ}

Trữ lạnh phôi là một kỹ thuật giúp bảo quản phôi trong một thời gian dài. Điều này có thể đạt được bằng cách lưu giữ các giao tử và phôi ở nhiệt độ của nitơ lỏng $\left(-196^{\circ} \mathrm{C}\right)$, làm ngưng các phản ứng enzyme nội bào, hô hấp, chuyển hóa..., giúp chúng vẫn tiếp tục phát triển bình thường khi rã đông sau 1 thời gian dài đông lạnh. Có nhiều yếu tố ảnh hưởng tới thành công của một chu kỳ chuyển phôi đông lạnh như: tuổi của mẹ, chất lượng niêm mạc tử cung của mẹ, chất lượng phôi sau rã đông,... Trong đó chất lượng phôi sau rã đông phụ thuộc vào kỹ thuật trữ lạnh và thời điểm trữ lạnh của phôi. Nếu sự ra đời của kỹ thuật đông phôi cực nhanh (vitrification) đã thể hiện ưu thế vượt trội trong kỹ thuật trữ lạnh thì cho đến nay việc trữ phôi vào giai đoạn nào tối ưu nhất vẫn còn đang tranh cãi.

Sự hiệu quả của nuôi cấy và chuyển phôi ngày 5 đã được chứng minh rõ ràng trong các báo cáo nghiên cứu trên toàn thế giới. Một tổng quan dựa trên 27 nghiên cứu được đăng tải trên tạp chí Cochrance 2016 cho thấy tỷ lệ thai lâm sàng và tỷ lệ sinh sống của chuyển phôi ngày 5 , 6 cao hơn so với chuyển phôi ngày 3 [5]. Như vậy có thể thây việc nuôi cãy phôi ngày 5 là lựa chọn tốt để nâng cao hiệu quả thành công của IVF thể hiện qua các khía cạnh như có thể chọn lựa được phôi khỏe, có khả năng làm tổ cao; chỉ cần chuyển $1-2$ phôi nhằm hạn chế tỷ lệ mang đa thai và an toàn trong quá trình đông lạnh phôi và rã đông phôi, tỷ lệ sống sau rã đạt gần $100 \%$. Một số nhà khoa học khác lại cho rằng chuyển phôi tươi ngày 3 và ngày 5 tỷ lệ có thai, tỷ lệ làm tổ khác nhau không có ý nghĩa thông kê, nhưng chuyển phôi đông lạnh ở nhóm bệnh nhân phôi ngày 5 chuyển số phôi ít hơn ngày 3 và có ý nghĩa thống kê [4].

Hiệu quả của nuôi cây và chuyển phôi ngày 5 đã được chứng minh rõ ràng trong các báo cáo nghiên cứu trên toàn thế giới. Tuy nhiên, chưa có nhiều công bố về hiệu quả của chuyển phôi nang trữ đông vì vậy nghiên cứu này nhằm cung cấp thêm thông tin khoa học về xu hướng mới này.

\section{II. ĐỐI TƯỢNG VÀ PHƯƠNG PHÁP NGHIÊN CỨU}

Nghiên cứu hồi cứu, đánh giá kết quả có thai của những trường hợp chuyển phôi nang trữ đông có tiên lượng khá trở lên tại Bệnh viện Hỗ trợ sinh sản và Nam học Đức Phúc từ tháng 1 đển tháng 8 năm 2021.

Đối tượng nghiên cứu: Là các trường hợp chuyển phổi nang trữ đông ngày 5,6 trong thời gian từ tháng 1 đến tháng 8 năm 2021.

Nghiên cứu được thực hiện theo phương pháp hồi cứu.

Tiêu chuẩn nhận: Những Bệnh nhân điều trị IVF/ICSI có chỉ định chuyển phồi nang trữ đông tại có đầy đủ các thông tin đầy đủ theo phiếu điều tra.

Tiêu chuẩn loại: Bệnh nhân PGD/PGS, bệnh nhân chuyển phôi tươi, các trường hợp không đủ thông tin

\section{Nhận định kết quả:}

Tiêu chuẩn đáng giá phôi: Sau khi rã đông ít nhất 3-4 giờ chúng tôi tiến hành đánh giá tỷ lệ phôi sống sau rã đông. Dựa theo các tiêu chí sự giãn nở khoang phôi, đánh giá nụ phôi hay còn gọi khối Inner Cell Mass (ICM) và đánh giá tế bào lá nuôi Trophectoderm (TE) [5].

Tiêu chuẩn đánh giá kết quả chuyển phôi đông lạnh.

Có thai: $\beta$ hCG sau 14 ngày chuyển phôi $\geq 25$ $\mu \mathrm{UI} / \mathrm{ml}$.

Thai lâm sàng: siêu âm túi ối có tim thai sau chuyển phôi đông lạnh 4 tuần.

Tỷ lệ thai lâm sàng: có túi ối, có tim thai/tổng số BN chuyển phôi.

Tỷ lệ thai sinh hóa là thai có $\beta$ hCG dương nhưng không thành thai lâm sàng.

Xử lý số liệu: Tiến hành nhập số liệu, xử lý số liệu bằng phần mêm SPSS 20.0 một cách lần lượt, hệ thống, tránh nhập thừa hay bỏ sót số liệu và vẽ biểu đồ bằng phần mềm Excel.

\section{KẾT QUẢ NGHIÊN CỨU}

1. Đặc điểm bệnh nhân. Từ tháng $1 / 2021$ đến tháng 8/2021, tại Bệnh viện Hỗ trợ và sinh 
VIETNAM MEDICAL JOURNAL N²2 - OCTOBER - 2021

sản có 365 trường hợp chuyển phôi nang trũ đông thỏa mãn tiêu chuẩn nghiên cứu. Các kết quả được thể hiện trong bảng 1 .

Bảng 1: Đặc điểm bệnh nhân và số phôi chuyển

\begin{tabular}{|c|c|}
\hline $\begin{array}{c}\text { Đặc điểm bệnh nhân } \\
\mathbf{n = 3 6 5}\end{array}$ & Kết quả \\
\hline Tuối trung bình & $33 \pm 6$ \\
\hline Số phôi chuyến trung bình & $1,86 \pm 0,42$ \\
\hline Số phôi tốt chuyển trung bình & $1,44 \pm 0,68$ \\
\hline
\end{tabular}

2. Tỷ lệ sống của phôi rã đông. Tống số có 365 chu kỳ có 685 phôi được rã đông phôi, sau rã đông ít nhất 3 giờ chúng tôi tiến hành đánh giá trên kính hiển vi đảo ngược, tiến hành nhanh trong vòng 2 phút. Đánh giá phôi sống dựa vào khoang giãn nở của phôi, lớp tế tào mầm (ICM), lớp tế bào lá nuôi TE.

Trong nghiên cứu này, số phôi sống 684 phôi chiếm tỷ lệ là 99,85\%. Tỷ lệ sống cao như vậy bởi chúng tôi đã áp dụng kỹ thuật đông rã thủy tinh hóa (Vitrification. Kỹ thuật này cho tỷ lệ sống cao hơn kỹ thuật đông phôi chậm nên số phôi sống sau rã đông là gần như $100 \%$. Tỷ lệ phôi sống cũng phụ thuộc vào kỹ năng thao tác, chất lượng của môi trường sử dụng.

3. Kết quả của chuyển phôi nang sau rã đông. Tỷ lệ $\beta-h C G$ dương tính và tỷ lệ thai lâm sàng của các bệnh nhân trong nghiên cứu lần lượt là $74,79 \%$ và $67,12 \%$. Tỷ lệ làm tổ của phôi là $40,35 \%$.

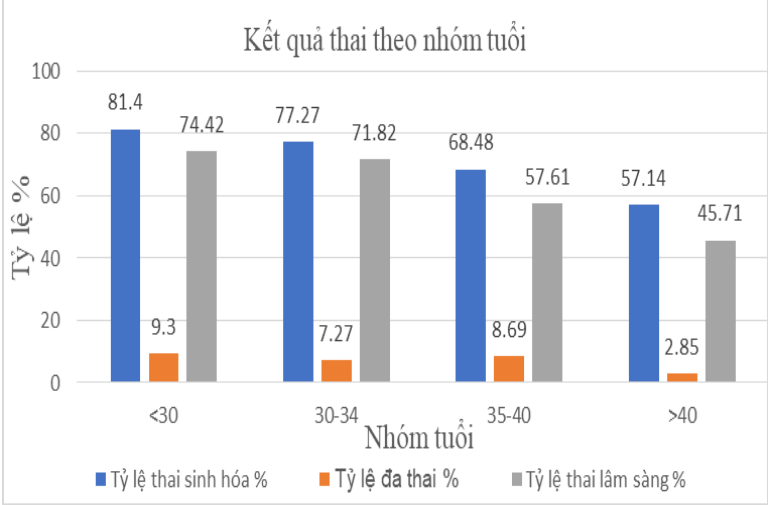

Biểu đồ 1: Thai theo nhóm tuổi

Kết quả nghiên cứu ở biểu đồ 1 cho thấy tỷ lệ thai sinh hóa, thai lâm sàng cao nhất nhóm tuối dưới 30 và giảm dần ở các nhóm, thấp nhất nhóm trên 40 tuổi. Tỷ lệ đa thai cũng cao nhất ở nhóm tuổi dưới 30 là 9.3\%.

4. Các yếu tố ảnh hưởng đến thai lâm sàng

*Sư tương quan giứa chất lượng phôi chuyển và thai lâm sàng

Bảng 2: Liên quan giữa chất lượng phôi chuyển và tý lệ thaî lâm sàng ở nhóm chuyển 2 phôi:

\begin{tabular}{|c|c|c|c|c|}
\hline $\begin{array}{c}\text { Chất } \\
\text { lượng } \\
\text { phôoi }\end{array}$ & $\begin{array}{c}\text { Có thai } \\
\text { lâm } \\
\text { sàng }\end{array}$ & $\begin{array}{c}\text { Không có } \\
\text { thai lâm } \\
\text { sàng }\end{array}$ & Tổng & $\begin{array}{c}\text { Giá } \\
\text { trị p }\end{array}$ \\
\hline 2L3 & 8 & 14 & 22 & \multirow{2}{*}{0.0023} \\
\hline $\begin{array}{c}\text { 1L1 hoắc L2 } \\
\text { +1L3 }\end{array}$ & 47 & 29 & 76 & \\
\hline 2L1 & 24 & 4 & 28 & \\
\hline Tống & $\mathbf{7 9}$ & $\mathbf{4 7}$ & $\mathbf{1 2 6}$ & \\
\hline
\end{tabular}

(Ghi chú: L1: Phôi tốt; L2: Phôi khá; L3: Phôi trung bình)

Tỷ lệ thai lâm sàng khi chuyển 2 phôi trung là $36,36 \%$ so với chuyển 1 phôi trung bình kèm 1 phôi khá hoặc tốt tỷ lệ thai lâm sàng là $61,84 \%$, đặc biêt khi chuyển cả 2 phôi tốt tỷ lệ thai lâm sàng là $85,71 \%$. Khi chúng tôi so sánh chuyển 2 phôi trung bình với chuyển 2 phôi có 1 phôi trung bình kèm với 1 phôi khá hoặc tốt thì tỷ lệ thai lâm sàng có sự khác biệt và sự khác biệt này có ý nghĩa thống kê $(p=0.0023)$

Bảng 3: Liên quan giữa chât lượng phôi chuyển và tỷ lệ thaỉ lâm sàng ở nhóm chuyển 1 phôi:

\begin{tabular}{|c|c|c|c|c|}
\hline $\begin{array}{c}\text { Chất lượng } \\
\text { phôii }\end{array}$ & $\begin{array}{l}\text { Có thai } \\
\text { lâm } \\
\text { sàng }\end{array}$ & $\begin{array}{l}\text { Không } \\
\text { thai lâm } \\
\text { sàng }\end{array}$ & Tổng & $\begin{array}{l}\text { Giá } \\
\text { trị p }\end{array}$ \\
\hline L3 & 1 & 11 & 12 & \\
\hline L1 hoặc L2 & 35 & 14 & 49 & \\
\hline Tống & 36 & 25 & 61 & 0.0001 \\
\hline
\end{tabular}

(Ghi chú: L1: Phôi tốt; L2: Phôi khá; L3: Phôi trung bình)

Kết quả phân tích từ nhóm chuyển 1 phôi trung bình cho kết quả thai lâm sàng chỉ đạt $8,3 \%$, khi chuyển 1 phôi là phôi tốt hoặc phôi khá thì tỷ lệ thai lâm sàng là đạt $71,43 \%$. Tỷ lệ có thai lâm sàng giữa hai nhóm này có sự khác biệt rõ rệt $(p=0.00065)$.

Thông qua kết quả nghiên cứu trên thì tỷ lệ có thai lâm sàng nhóm 1 phôi tốt hoặc khá so với nhóm chuyển 2 phôi khá và tốt là khá cao. Chuyển 2 phôi cho kết quả cao hơn chút, và trường hợp tiên lượng chuyển tốt chúng ta có thể chuyển 1 phôi tốt hoặc khá. Còn trường hợp chuyển có phôi loại trung bình chúng ta nền chuyền kèm 1 phôi loại1, loại 2, hoặc loại 3 để có tỷ lệ thai lâm sàng cao, mà tránh được các trường hợp đa thai.

*Tương quan tuổi của người vợ với thai lâm sàng. Đã có nhiều nghiên cứu chỉ ra rằng phụ nữ càng lớn tuổi thì cho tỷ lệ thành công trong IVF càng giảm. Trong nghiên cứu của chúng tôi thấy rằng tỷ lệ có thai lâm sàng ở nhóm từ 35 tuổi trở xuống cao hơn so với những bệnh nhân có tuổi trên 35 tuổi. Tỷ lệ có thai lâm 
sàng 2 nhóm lần lượt là: 73,95\% và 54,33 hiệu quả có thai lâm sàng ở nhóm tuổi dưới 35 cao gấp 1,358 lấn so với nhóm tuổi trên 35 . Sự khác biệt này có ý nghĩa thống kê với $p=0.03<0.05$; $\mathrm{OR}=0.489 ; \mathrm{CI}=0.04727-0.2339$ (Bảng 3).

Sự tương quan số lượng phôi chuyển và thai lâm sàng. Hiệu quả có thai lâm sàng khi chuyển 1 phôi tốt là $71,43 \%$, chuyển 1 trung bình là $8,3 \%$. Như vậy chuyển 1 phôi tốt so với một phôi 1 xấu tỷ lệ thai lâm sàng cao gấp 8,6 lần. Như vậy hiệu quả có thai lâm sàng khi chuyển 1 phôi tốt so với 1 phôi trung bình cao hơn có sự khác biệt với độ tin cậy $p=0.00<0.05$, CI từ 0.04-0.309 $\mathrm{OR}=27.50$ và có ý nghĩa thống kê.

Phân tích kết quả thấy được hiệu quả giữa nhóm chuyển 1 phôi tốt bảng 3 có $O R=0.299$ so với chuyển 2 phôi trung bình bảng 2 kết quả có thai lâm sàng so với nhóm có 2 phôi trung bình $\mathrm{p}=0.08$ nhưng $\mathrm{OR}=0.299$ nằm trong $0.95 \mathrm{CI}$ từ 0.079-0.664, nên sự khác biệt này có ý nghia thống kê.

Hiệu quả chuyển 2 phôi( có 1 phôi khá hoặc 1 phôi tốt) có $\mathrm{OR}=0.353$ với chuyển 2 phôi trung bình như bảng 2 tỷ lệ thai lâm sàng tăng lên 1,7 lần. Sự tăng lên có độ tin cậy $p=0.05, C I \quad 0.132-$ 0.943 , p nằm trong $\mathrm{CI}$. Hiệu quả khi chuyển 2 phôi, có 1 phôi khá hoặc tốt so với nhóm chuyển 2 phôi trung bình tỷ lệ có thai lâm sàng tăng lên có ý nghĩa thống kê.

Dựa trên sự tương quan số lượng, chất lượng, một lần nữa khẳng định với phồi có chất lượng tốt, khá, các yếu tố lâm sàng có tiên lượng tốt chúng tôi đưa ra kiến nghị chỉ chuyển 1 phôi, những trường hợp phôi trung bình chúng ta có thể chuyển 2 phồi hoặc 1 phôi trung bình kèm thêm 1 phôi khá hoặc tốt.

\section{BÀN LUẬN}

Hiện nay, thủy tinh hóa đang dần chiếm ưu thế do hiệu quả bảo quản phôi của phương pháp này mang lại (Rezazadeh V. và cs. (2009), Giovanna F. và cs. (2014), Rienzi L. và cs. (2016)). Theo nghiên cứu của chúng tôi, phôi được đông-rã theo phương pháp thủy tinh hóa, có tỷ lệ phôi sống sau rã đông là $99,85 \%$. Đây là một tỷ lệ sống cao, khẳng định được tính ưu việt của phương pháp đông phôi thủy tinh hóa cũng như khả năng thực hiện kỹ thuật đông phôi tại Bệnh viện Hỗ trợ sinh sản và Nam học Đức Phúc. Đã có tác giả báo cáo thủy tinh hóa làm tăng tỷ lệ sống và ảnh hưởng đáng kể đến trọng lượng trẻ sơ sinh[8].

Theo kết quả của một số báo cáo về chuyển phôi ngày 5 mới nhất tại các hội nghị khoa học trong nước, chúng tôi nhận thấy số phôi nang chuyển một số nơi còn nhiều. Tỷ lệ có thai lâm sàng chung của chúng tôi dao động khoảng 50$64,68 \%$ và cao hơn một số trung tâm. Số lượng phôi chuyển trung bình tại labo chúng tôi là 1,86 $\pm 0,42$ (bảng 4). Tỷ lệ $\beta$-hCG dương tính và tỷ lệ có thai lâm sàng của nhóm nghiên cứu lần lượt là $74,79 \%$ và $67,12 \%$.

Bảng 4: Kết quả chuyển phôi nang của một sốtrung tâm HTSS

\begin{tabular}{|c|c|c|c|}
\hline \multirow{2}{*}{ Đặc Điểm } & \multicolumn{2}{|c|}{$\begin{array}{c}\text { Chuyển phôi } \\
\text { ngày 5 }\end{array}$} & $\begin{array}{c}\text { IVF Đức } \\
\text { Phúc } \\
\text { EF5 Đức } \\
\text { Phúc }\end{array}$ \\
\cline { 2 - 4 } & $\begin{array}{c}\text { Minh và } \\
\text { cs (2012) } \\
\text { [2] }\end{array}$ & $\begin{array}{c}\text { Hiền và } \\
\text { cs(2012) } \\
\text { [1] }\end{array}$ & $\mathbf{2 0 2 1}$ \\
\hline Số trường hợp & 175 & 99 & 365 \\
\hline $\begin{array}{c}\text { Số phôi chuyến } \\
\text { trung bình }\end{array}$ & $3,5 \pm 1$ & $1,4 \pm 0,9$ & $\begin{array}{c}1,86 \pm \\
0,42\end{array}$ \\
\hline Tỷ lệ Beta (\%) & 46,24 & 49,5 & 74,79 \\
\hline $\begin{array}{c}\text { Thai lâm sàng } \\
\text { (\%) }\end{array}$ & 42,85 & 43,9 & 67,12 \\
\hline
\end{tabular}

Số phôi chuyển của chúng tôi tương đương và thấp hơn. Nhưng tỷ lệ thai $\beta-h C G$, tỷ lệ có thai lâm sàng của chúng có sự tăng lên đáng kể.

Trong một nghiên cứu mới nhất của Wang $\mathrm{N}$ và cộng sự công bố tháng 4 năm 2021. Kết quả nghiên cứu chuyển 6077 chu kỳ chuyển đơn phôi thì chuyển phôi nang tốt làm tăng tỷ lệ có thai lâm sàng và thai sinh sống[7]. Chuyển phôi nang tỷ lệ thai lâm sàng, thai sinh sống tăng, giảm tỳ lệ đa thai [3].

So với chuyển phôi nang, chuyển phôi giai đoạn phân chia đơn giản và thuận tiện hơn. Việc nuổi cấy phôi đơn giản, không đòi hỏi nhiều tủ cấy riêng biệt, công việc của lab ít hơn, quy trình đối với bệnh nhân đơn giản hơn, tác động của sự không ổn định của hệ thống nuôi cãy lền kết quả ít hơn. Trong nuôi cấy phôi nang, để kết quả nuôi cấy ổn định, tỉ lệ phát triển phôi nang cao, duy trì khả năng sống của phôi và giảm các tác động bất lợi lên quá trình phát triển của phôi, đòi hỏi phải có một hệ thống nuôi cây phôi hoàn chỉnh với các quy trình kiểm soát chất lượng tốt. Chi phí đầu tư cho hệ thống này là rất tốn kém.

Ngoài ra, theo kinh nghiệm của chúng tôi thì có một số yếu tố chúng tôi cho rằng liên quan đến hiệu quả chuyển phôi nang trữ đông dưới đây:

Một là: sau rã đông ít nhất 3-4 tiếng chúng tôi tiến hành đánh giá và chụp hình ảnh phôi trên kính hiển vi đảo ngược trong vòng nhỏ hơn 2 phút. Thời gian như vậy để phôi có thời gian giãn nở khoang to rộng như trước đông. 
Hai là: Khi chuẩn bị hồ sơ rã tùy theo chất lượng phôi, khoang phôi chúng tôi tính thời gian rã, làm sao sau rã đến lúc chuyển đạt khoảng thời gian 3-4 tiếng, đặc biệt hạn chế tối đa chuyển phôi đã thoát màng.

Ba là: Chúng tôi thường xuyên kiểm soát chặt điều kiện phòng lab,

\section{KẾT LUÂNN}

Tỷ lê phôi sống sau rã đông của chúng tôi đat $99,85 \%$. Tỷ lệ $\beta$-hCG dương tính 74,79\% và tỷ lệ thai lâm sàng $67,12 \%$. Tỷ lệ làm tổ của phôi là 40,35\%.

Dựa trên các kết quả thu được chúng tôi cho rằng các trung tâm cần được đầu tư kỹ lưỡng về nhân lực, hệ thống nuôi cấy tốt và áp dụng thường quy việc nuôi và chuyển phôi nang. Tuy nhiên việc nuôii cấy và chuyển phôi nang chỉ ưu tiên các trường hợp tiên lượng tốt.

Tỷ lệ có thai lâm sàng khi chuyển 1 phôi là 71,43\%, bệnh nhân dưới 30 tuổi tiên lượng tốt nên tư vấn chuyển 1 phôi nhằm mục đích tránh đa thai và sinh non cũng như nhiều nguy cơ khác.

Tỷ lệ có thai lâm sàng còn liên quan đến một số yếu tố như tuổi người mẹ, kỹ thuật và thời điểm đông, rã, thời gian sau rã đông cho đến khi chuyển phôi cũng như các điều kiện phòng thí nghiệm.

\section{TÀI LIÊU THAM KHẢO}

1. Hiền Thu Thị Bùi, Kết quả chuyển phôi ngày 5 tại IVF Vạn Hạnh, IVF Expert meeting 8, 2012, 143-146.

2. Nguyến Thi Minh, Đánh giá hiêu quả chuyển phôi ngày 5, IVF Expert meeting 8, 2012, 55-62 5.

3. Ariel Weissman et al., Blastocyst culture and transfer: lessons from an unselected, difficult IVF population, RBM Online, 2008, Vol 17, No 2, 220-228

4. E.M.Kolibainakis, et al (2004) "Should we advise patients undergoing IVF to start cycle leading to a day 3 or a day 5 transfer" Human Reproduction Vol.19, No.Il pp. 2550-2554.

5. https://www.cochrane.org/CD002118/MEN STR_blastocyst-versus-cleavage-stage-embryotransfer-assisted-conception

6. Magli M, Gayle J, Kersti L et al. The atlas of human embryology from oocytes to preimplantation embryos. Oxford University Press, UK; 2012

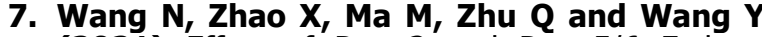
(2021) Effect of Day 3 and Day 5/6 Embryo Quality on the Reproductive Outcomes in the Single Vitrified Embryo Transfer Cycles. Front. Endocrinol. 12:641623. doi: 10.3389/ fendo.2021.641623

8. Zhang J, Wang $Y$, Liu HF, Mao XY, Chen QJ, Fan Y. Effect of In Vitro Culture Period on Birth Weight After Vitrified-Warmed Transfer Cycles: Analysis of 4,201 Singleton Newborns. Fertil Steril (2019) 111(1):97-104. doi: 10.1016/j. fertnstert.2018.10.006 PubMed Abstract | CrossRef Full Text | Google Scholar

\section{TÌNH HÌNH THEO DÕI THAI PHỤ NHIỄM HIV/AIDS TẠI BỆNH VIỆN PHỤ SẢN TRUNG ƯO'NG}

\section{TÓM TẮT}

Muc tiêu: Nhân xét thực trang khám thai của thai phu nhiễm HIV/AIDS tại BVPSTW. Phương pháp: Nghiên cứu hồi cứu mô tả. Kết quả: Tuổi trung bình của thai phu nhiếm HIV là $32,55 \pm 5,4$. Nhóm tuổi $\geq$ 35 tuổi chiếm tỉ lệ cao nhất 40,6\%. Thai phụ sinh con so là $31,5 \%$ và sinh con da là $68,5 \%$. Thai phu có khám và quản lý thai nghén là $91,5 \%$; trong đó tỷ lệ quản lý thai nghén tai BVPSTW là $42,4 \%$. Thời điểm phát hiện nhiếm HIV trước có thai là $73,3 \%$, trong khi có thai là $15,8 \%$ và ngay trước chuyển da là $10,9 \%$.Tỷ lệ điều trị dự phòng ARV cho thai phụ là $99,4 \%$. Thai phụ được điều trị ARV trước có thai là $70,9 \%$, trong khi có thai là $15,2 \%$ và khi chuyển dạ là $13,3 \%$. Kết

\footnotetext{
${ }^{1}$ Bệnh viện đa khoa Phúc Lâm

${ }^{2}$ Trường Đai hoc Y Hà Nôi

Chịu trách nhiệm chính: Đỗ Thu Huyền

Email: dothuhuyen301189@gmail.com

Ngày nhận bài: 26.7.2021

Ngày phản biên khoa họ: 27.9.2021

Ngày duyệt bài: 1.10.2021
}

\section{Đỗ Thu Huyền', Lê Thị Thanh Vân ${ }^{2}$}

luận: Thai phụ nhiễm HIV có khám và quản lý thai nghén chiếm tỳ lê cao $91,5 \%$. Thai phu phát hiên nhiếm HIV trước khi mang thai là 73,3\%. Tỷ lệ điều trị dự phòng ARV cho thai phụ là $99,4 \%$ và thai phụ điêu trị PLTMC từ trước khi có thai là 70,9\%.

Tư khóa: HIV, phòng lây truyền mẹ con.

\section{SUMMARY \\ MONITORING STATUS OF PREGNANT \\ WOMEN INFECTED WITH HIV/AIDS AT THE NATIONAL HOSPITAL OF OBSTETRICS AND GYNECOLOGY}

Objective: To assess the status of antenatal care of pregnant women infected with HIV/AIDS at the National Hospital of Obstetrics and Gynecology. Method: Descriptive retrospective study. Results: The mean age of pregnant women infected with HIV was 32.55 years (SD \pm 5.4 years). The age group over 35 years old accounted for the highest rate of $40.6 \%$. Pregnant women giving birth for the first time is $31.5 \%$ and $68.5 \%$ of women had had one more pregnancy. Pregnant women with pregnancy examination and management are $91.5 \%$, of which 